\title{
A MEDIAÇÃO JUDICIAL COMO ALTERNATIVA PARA ATENUAR A CRISE NUMÉRICA DE PROCESSOS
}

Diego Bianchi de Oliveira ${ }^{1}$

OLIVEIRA, D. B. de. A mediação judicial como alternativa para atenuar a crise numérica de processos. Rev. Ciênc. Juríd. Soc. UNIPAR. Umuarama. v. 22, n. 2, p. 317-331, jul./dez. 2019.

RESUMO: O Novo Código de Processo Civil apresenta a mediação como uma das novidades introduzidas; o presente trabalho faz uma breve análise sobre essa inovação, abordando suas peculiaridades. Assim, questiona-se se esse novo instrumento será capaz de atenuar a problemática da crise numérica de processos e proporcionar uma prestação jurisdicional efetiva. E ainda, analisa-se se mediação proporcionará o efetivo acesso à justiça, de modo a satisfazer as tutelas que sobrecarregam ao Poder Judiciário.

PALAVRAS-CHAVE: Acesso à justiça; Mediação judicial; Crise numérica de processos.

\section{LEGAL MEDIATION AS AN ALTERNATIVE TO REDUCE THE LAWSUIT NUMERICAL CRISIS}

\begin{abstract}
The New Code of Civil Procedure presents mediation as one of the new features; this study briefly analyzes this novelty, addressing its peculiarities. Thus, it questions whether this new instrument will be able to mitigate the issue of the lawsuit numerical crisis and provide an effective jurisdictional provision. In addition, it analyzes whether mediation will provide effective access to justice, in order to satisfy the protections that overload the Judiciary Branch.

KEY WORDS: Access to justice; Judicial mediation; Lawsuit numerical crisis.

\section{MEDIACIÓN JUDICIAL COMO ALTERNATIVA PARA ATENUAR LA CRISIS NUMÉRICA DE PROCESOS}

RESUMEN: El Nuevo Código de Procedimiento Civil presenta la mediación como una de las novedades introducidas, esta investigación hace un breve análisis sobre esa innovación, abordando sus peculiaridades. Por lo tanto, se cuestiona si ese nuevo instrumento podrá atenuar el problema de la crisis numérica de

\footnotetext{
${ }^{1}$ Mestre em Direito pela UNIPAR (2016). Especialista em Direito Imobiliário pela UCAM (2014). Graduado em Direito pela UEMS (2013). Graduado em Administração pela Anhanguera-UNIDERP (2009). Professor dos cursos de Direito e Administração. Advogado. diegobianchi@hotmail.com
} 
procesos y proporcionar una disposición jurisdiccional efectiva. Aún, se analiza si la mediación proporcionará acceso efectivo a la justicia, a fin de satisfacer las tutelas que sobrecargan el Poder Judicial.

PALABRAS CLAVE: Acceso a la justicia; Mediación judicial; Crisis numérica de procesos.

\section{INTRODUÇÃO}

É notório o crescente acesso da população ao Judiciário, em contrapartida, a qualidade dos serviços prestados decaiu muito, tornando-se insuficiente para satisfazer a demanda, especialmente por falta de estrutura material e de pessoal, além de uma legislação processual inadequada aos novos desafios institucionais.

$\mathrm{O}$ volume de processos judiciais tem crescido ano a ano e, ainda que haja aumento do número de decisões judiciais, os números continuam a evidenciar uma grave crise na prestação jurisdicional e tornam-se necessárias ações que sejam capazes de atenuar essa crescente demanda.

Assim, evidencia-se o surgimento de um grave problema contemporâneo: a crise numérica de processos, decorrente do crescimento do acesso da população ao Judiciário. Esse problema requer a adoção de medidas alternativas para a redução das demandas judiciais, vez que, seria muito oneroso criar uma nova estrutura para que o Judiciário possa atender essa demanda gigantesca.

Devido a isso, e com a inovação trazida pelo novo Código de Processo Civil (CPC), busca-se nesta pesquisa, analisar o instituto da mediação judicial, apresentada como alternativa para atenuar o problema da crise numérica de processos que assola o Poder Judiciário.

O presente artigo pretende trazer uma melhor compreensão acerca da mediação, como método alternativo de resolução de conflitos, conforme a Lei $\mathrm{n}^{\mathrm{o}}$ 13.140/2015, que regulamenta o método, e o novo Código de Processo Civil. Ressaltando ainda a importância da figura do mediador, como peça fundamental na intermediação das partes para uma composição consensual.

Desta forma, pretende-se estudar o modo como a mediação pode apresentar-se como método alternativo para a resolução dos conflitos e ainda, como auxilia na consolidação do acesso à justiça.

O trabalho se desenvolveu com a pesquisa realizada e estruturada com base em fontes especializadas no âmbito do Direito Processual Civil, Direito Constitucional, Direito Civil, realizando-se pesquisas específicas acerca do tema, por meio de leituras das obras indicadas na bibliografia básica, visando a construção de uma visão geral do tema. 


\section{ACESSO À JUSTIÇA}

Preliminarmente, antes de tratar da Mediação, é importante verificar a relevância constitucional do princípio do Acesso à Justiça, já que, referido princípio ganhou novos moldes nos últimos tempos, de modo que não deve ser concebido como mera admissão ao processo, mas como pacificação com justiça (CINTRA; DINAMARCO; GRINOVER, 2005, p. 35-36)

O princípio do Acesso à Justiça previsto na Constituição Federal, em seu artigo $5^{\circ}, \mathrm{XXXV}$, enuncia que a lei não excluirá da apreciação do Poder Judiciário lesão ou ameaça a direito. Assim, esse princípio não faz menção apenas à inafastabilidade do acesso ao Judiciário, mas uma tutela jurisdicional efetiva, adequada e tempestiva que tenha como resultado a ordem jurídica justa.

Assim, ao proibir os cidadãos de resolverem por si seus conflitos de interesse, o Estado assumiu o poder de resolvê-los, todavia, adquiriu também o dever de prestar certo serviço público, que é a jurisdição (ASSIS, 1999, p. 09). Dessa forma, para o surgimento de um novo conceito de acesso à justiça, leva-se em consideração o papel do Estado que deve assegurar que todos os indivíduos possam reivindicar seu direito à jurisdição.

Do mesmo modo, Capelletti (1988, p. 38) afirma que o acesso ao judiciário já é uma realidade, entretanto, esse acesso, isoladamente, não alcança a plenitude desejada pelo Estado Democrático de Direito, de modo que, o simples fato de assegurar ao cidadão o seu direito de acesso à Justiça não lhe garante que haverá justiça.

Ademais, o Estado deve encarar esse direito de ação assegurando a qualquer um o direito de provocar o Judiciário, não garantindo o provimento daquilo que é pedido, mas sim voltado para a realização da justiça. O Estado, ao ser provocado, tem a obrigação de prestar a jurisdição de forma efetiva, consoante afirmação de Marinoni (2004), essa "prestação efetiva da tutela do direito depende do provimento adequado, é claro que não há como falar em direito à tutela sem pensar em direito ao provimento que seja capaz de prestá-la".

Ao tecer análise acerca do atual conceito de acesso à justiça, verifica-se que está vinculado à concepção de que a resolução do caso concreto pelo judiciário depende da aptidão dos meios e procedimentos utilizados, só assim poderá efetivar uma tutela adequada, efetiva e em tempo razoável ao direito pleiteado. Nesse sentido, os professores Medina e Wambier (2013) apontam que:

O direito à tutela jurisdicional somente terá sido satisfeito de modo apropriado se o Estado oferecer às partes tutela jurisdicional adequada às situações de direito material que forem submetidas. O direito de ação, assim, compreende não apenas a tutela jurisdicional adequada, mas tam- 
bém um processo adequado.

Deste mesmo entendimento, corroboram Marinoni e Arenhart (2013):

O direito de ação, atualmente, deve permitir ou viabilizar o efetivo alcance das tutelas prometidas pelo direito material. Deve "permitir ou viabilizar" porque a tutela do direito somente é prestada quando o direito material é reconhecido no caso concreto. Mas, quando o direito é reconhecido, a tutela jurisdicional há de ser efetiva.

A celeridade também é de extrema importância, pois a prestação jurisdicional em tempo razoável é direito fundamental que está previsto no inciso LXXVIII, do art. $5^{\circ}$, da Constituição Federal. Esse direito assegura a todos a razoável duração do processo e instrumentos que garantam a celeridade de sua tramitação, e ainda, torna possível a punição de condutas praticadas tanto pelas partes quanto pelo juiz, que objetivem apenas protelar o andamento e o resultado do processo.

Percebe-se que o desenvolvimento do conceito de acesso à justiça vai além daquele primordial de que o Judiciário deveria abrir suas portas à população, mas sim proporcionar uma resolução efetiva e eficaz aos cidadãos, com celeridade.

Assim, proporcionando uma tutela jurisdicional adequada, efetiva e tempestiva, poderá ser eliminado o antigo conceito de acesso à justiça como mero acesso ao judiciário. Nesse contexto, Watanabe (1988) assevera que "não se trata somente de possibilitar o acesso à justiça enquanto instituição estatal, mas de viabilizar o acesso à ordem jurídica justa".

E ainda, Moralles (2006, p. 52-53) define o acesso à ordem jurídica justa como o "[...] acesso a uma ordem de valores e direitos selecionados pela sociedade que permitam a realização do ideal justiça social, oportunidades equilibradas aos litigantes, participação democrática e tutela jurisdicional efetiva".

Assim, o Estado deve buscar mecanismos que viabilizem, facilitem, e garantam o acesso à justiça, considerando-se que sua obrigação vai além de simplesmente prestar a tutela jurisdicional. Cabe ao Estado, além de receber as demandas judiciais, garantir que sejam julgadas, ou prevenir para que os conflitos não sejam reiteradamente transformados em ações judiciais, viabilizando a criação de medidas alternativas para solução destes.

Diante desse quadro, na iminência da entrada em vigor do novo CPC, que traz como novidade o instituto da mediação, que poderá proporcionar às partes, além do acesso à justiça, também uma resolução do conflito de forma eficaz e célere, através da autocomposição das partes. Por meio da aplicação desse 
novo instituto espera-se que parte seja fortalecido o acesso à justiça, aplicando um método mais rápido e diminuindo o número de ações que tramitam por longo tempo no judiciário.

\section{MEDIAÇÃO JUDICIAL: A PROPOSTA DO NOVO CPC}

Com uma explosão de ações judiciais, verifica-se que a população simplesmente entendeu que as portas do Judiciário realmente estavam abertas para receber todos os conflitos, resultando no congestionamento do Judiciário. Assim, ao longo dos anos, o excesso de processos tem onerado servidores e magistrados, que já não suficientes para atender a uma demanda que aumenta cada vez mais.

Ainda persiste a prática de levar o problema para que um terceiro, o juiz togado, possa resolvê-lo, o que acaba mantendo o caráter conflituoso da relação. E assim, milhares e milhares de ações judiciais vão se formando e são levadas ao Judiciário, o que prejudica a eficácia efetiva, adequada e tempestiva, enquanto processos se arrastam por anos e as partes permanecem insatisfeitas e ainda em conflito.

Nesse diapasão, Rocha e Salomão tecem as seguintes considerações:

Há vários fatores para a explosão da litigiosidade no Brasil. Com a Constituição de 1988, na esteira da democratização do país, foram criados novos direitos, nem todos com a clara indicação de meios para assegurá-los, fenômeno que contribui para a crescente judicialização de conflitos, muitos deles relativos à formulação e execução de políticas públicas.

Nesse cenário, frequentemente são tomadas medidas a fim de viabilizar o desafogamento do judiciário, na tentativa de proporcionar maior celeridade na resolução das mais diversas lides. Esse judiciário tão sobrecarregado perde cada vez mais a credibilidade, pois a demora na resolução de litígios, pela via judicial, deixa os cidadãos sem muitas esperanças, pois aquele que deseja uma rápida solução para sua lide acaba presenciando o andamento de um processo por anos e anos.

Diante dessa problemática, a Lei $\mathrm{n}^{\mathrm{o}} 13.105 / 2015$, o novo Código de Processo Civil, que deverá entrar em vigor em 2016, tem como uma de suas bases a busca pela resolução consensual de conflitos, principalmente por meio da mediação, que é citada em vários dispositivos do referido código.

E ainda, sancionada a Lei ${ }^{\circ}$ 13.140/2015 (Lei de Mediação), a mediação ganhou um marco legal próprio, vez que a citada lei regulamenta a mediação entre particulares como meio de solução de controvérsias, e sobre a autocompo- 
sição de conflitos no âmbito da administração pública.

Nesse contexto, surgiu a mediação judicial como alternativa para diminuir as demandas judiciais e atenuar o problema da crise numérica de processos. Assim, a resolução dos conflitos por meio da mediação é defendida como uma boa alternativa, sendo capaz de aliviar os tribunais da excessiva carga de trabalho que lhes é imposta, tornando-se uma estratégia governamental fundamental para garantir que as disputas sejam resolvidas de modo mais justo, rápido e eficiente, sem a necessidade de submissão às etapas de um processo judicial (ALMEIDA, 2015, p. 1).

Como proposta inovadora, a medição vem propor uma mudança de mentalidade, em que se pretende devolver às partes a capacidade de resolver seus próprios conflitos, utilizando-se de técnicas e princípios aplicados pelos mediadores, que serão os responsáveis pela realização da mediação.

Esse método irá dispensar a tramitação de um longo processo judicial e o novo CPC traz previsão legal para que a mediação torne-se, inclusive obrigatória nas ações de família, de modo a tornar-se a primeira via que irá socorrer as partes para a solução do problema.

A mediação e a Conciliação são instrumentos de pacificação de conflitos, capazes de simplificar as demandas. Como novos institutos no cenário jurídico ainda precisam de maior divulgação, pois a utilização destes novos meios poderá contribuir para uma maior celeridade na justiça.

Com relação à celeridade, é necessário ressaltar que a mediação dispensa o rito inicial de um processo judicial, sendo desnecessária a produção de provas. Ademais, as partes não aguardarão anos por uma sentença que irá confirmar o direito de um e deixar a parte perdedora inconformada.

A mediação é definida como um dos meios alternativos para resolução de conflitos, muito enfatizada pelo legislador e merecedora de grande análise. A própria Lei $\mathrm{n}^{\circ} 13.140 / 2015$ a regulamente e conceitua no seu Art. $1^{\circ}$, Parágrafo Único, como "a atividade técnica exercida por terceiro imparcial sem poder decisório, que, escolhido ou aceito pelas partes, as auxilia e estimula a identificar ou desenvolver soluções consensuais para a controvérsia".

Lilia Sales também conceitua mediação:

[...] procedimento consensual de solução de conflitos por meio do qual uma terceira pessoal imparcial - escolhida ou aceita pelas partes - age no sentido de encorajar e facilitar a resolução de uma divergência. As pessoas envolvidas nesse conflito são as responsáveis pela decisão que 
melhor a satisfaça. A mediação representa um mecanismo de solução de conflitos utilizado pelas próprias partes que, motivadas pelo diálogo, encontram uma alternativa ponderada, eficaz e satisfatória. O mediador é a pessoa que auxilia na construção desse diálogo...] (SALES, 2004, p.23).

Assim, a mediação pode ser entendida como uma modalidade de autocomposição voluntária, buscada por ambas as partes, ou, ao menos, de iniciativa de uma parte, mas contando sempre com a anuência da outra. Também se caracteriza como um processo legítimo de promoção da Justiça, não conflituosa, confidencial e voluntária, utilizando-se de um terceiro imparcial, isento e desinteressado, que exerce a função de mediador.

No novo Código de Processo Civil os institutos da conciliação e da medição estão dispostos nos artigos 165 a 175. Referente à mediação, é voltada à atividade praticada dentro da estrutura do Poder Judiciário, o que não exclui, contudo, a mediação prévia ou mesmo a possibilidade de utilização de outros meios de solução de conflitos.

A mediação está pautada pelos seguintes princípios: voluntariedade, confidencialidade, participação de terceiro imparcial, economia financeira e de tempo, informalidade, reaproximação das partes, autonomia das decisões/Autocomposição e não-competitividade.

Alguns aspectos positivos na mediação podem ser destacados: a diminuição dos custos inerentes à resolução de conflitos, bem como a redução do tempo médio; o controle dos procedimentos por parte dos participantes, desde o início até o fim, já que a decisão de iniciar ou pôr fim à mediação será sempre decisão das partes, através de um procedimento flexível e informal.

Outro aspecto de grande relevância na mediação, é que, sendo o acordo construído pelas partes através do diálogo, a resolução do conflito terá mais efetividade, já que ambos sairão satisfeitos com o acordo realizado. Consoante assevera Leite (2008, p.108) "a mediação tem como objetivo: a responsabilização dos protagonistas, capazes de elaborar, eles mesmos, acordos duráveis. Um trunfo da mediação é a restauração do diálogo e da comunicação, alcançando sua pacificação duradoura".

Ainda assim, apesar de todos os benefícios proporcionados, a medição não deve ser vista como o remédio capaz de solucionar qualquer conflito, ou instrumento capaz de resolver a crise do Judiciário, mas sim, como uma medida inicial que pode colocar fim à lide existente, antes mesmo do início do processo judicial.

Nesse sentido, assevera Almeida (2015, p. 13): 
A intenção não é a defesa do fim da jurisdição como forma de resolver controvérsias, tampouco imaginar que demais mecanismos serão a solução definitiva para a solução da crise do Estado-juiz, mas sim conscientizar o Poder Judiciário de que o cumprimento de seus papel constitucional garantidor de uma atividade jurisdicional efetiva não consiste necessariamente na intervenção em todo e qualquer conflito, mas intervir quando necessário, como última ratio.

Diante de todo o exposto, é possível vislumbrar na mediação uma alternativa capaz de atenuar a problemática da crise numérica de processos, uma forma inicial de resolução de conflitos em que as partes tomarão para si a resolução de seus problemas, sendo auxiliadas pelo mediador, buscando-se a melhor solução para ambos e construindo um acordo com validade jurídica.

Por outro lado, diminuindo-se a quantidade de processos que realmente precisam da decisão de um juiz togado, o Judiciário poderá focar no julgamento das ações que realmente necessitam de sua intervenção, e com isso, poderá haver mais celeridade.

\subsection{A importância do mediador}

O mediador é um terceiro imparcial, não interessado que auxiliará as partes na busca de uma solução viável para ambos, aplicando princípios e método apropriado, facilitando o entendimento entre as partes.

Em muitos casos há entre as partes uma ausência total de comunicação, e diante de uma lide, torna-se mais fácil acionar o judiciário para que resolva esse conflito a simplesmente conversar e chegar a um consenso do que é melhor para ambos. Diante disso, o mediador vai atuar estabelecendo a comunicação entre as partes e verificando o que cada um realmente deseja com a ação judicial que está propondo e auxiliá-los a buscar uma solução que satisfaça ambos.

Caio Cesar Vieira Rocha (2015, p. 227) tece importante consideração acerca do papel do mediador:

$\mathrm{O}$ mediador tem a incumbência de clarificar as razões reais da disputa e as possíveis soluções e, considerando o eventual nível de hostilidade entre as partes, trabalhar para que as discussões ocorram com urbanidade e respeito recíprocos, inclusive para que cada uma das partes possa discernir quais são seus interesses reais e suas paixões momentâneas. No curso de um processo judicial adversarial dificilmente o magistrado conseguiria assumir essa 
incumbência de distensionamento das partes.

Consoante dispõe a Lei de mediação, o mediador judicial deve ter curso superior completo, formado há pelos menos dois anos em instituição reconhecida pelo Ministério da Educação, e estar capacitado em uma escola de formação de mediadores reconhecida pela Escola Nacional de Formação e Aperfeiçoamento de Magistrados ou pelos tribunais.

Como principais características, o mediador deve ser neutro e imparcial, pois atuará como facilitador entre duas partes em conflito e de maneira alguma poderá apresentar qualquer tendência de proteger ou acusar qualquer das partes. E ainda, o mediador deve agir respeitando alguns fundamentos da mediação: a confidencialidade, controle emocional, capacidade de escuta ativa, equilíbrio das negociações.

Finalmente, ressalta-se que em uma sessão de mediação, atuarão dois mediadores, ambos atuando como facilitadores da comunicação entre as partes, direcionados por princípios e utilizando-se de técnicas específicas que auxiliarão na dissolução do conflito, sem que haja qualquer hierarquia entre eles. Apenas atuarão em duplas para que prestem auxilio um ao outro e cada um tenha sua percepção diante dos fatos narrados pelas partes.

\section{A CRISE NUMÉRICA DE PROCESSOS: A MEDIAÇÃO JUDICIAL COMO ALTERNATIVA}

A crise numérica de processos é um problema que prejudica diretamente o acesso à justiça, isso porque, enquanto houver uma demanda excessiva, haverá dificuldade em estruturar o Judiciário adequadamente, com um número satisfatório de servidores e Juízes para movimentar e julgar todos os processos em andamento.

Dessa forma, vislumbrando amenizar essa crise numérica, a mediação surge como uma forma inicial e alternativa de tentar colocar fim à lide existente antes mesmo que haja necessidade de produção de provas, mediando as partes, reestabelecendo a comunicação entre elas para que cheguem a um acordo que seja satisfatório para ambos.

Nesse sentido, leciona Caio Cesar Vieira Rocha (2015, p. 234).

O mundo contemporâneo pede concisão e, acima disso, requer a construção de pontes e canais mais adequados para prevenção e composição de conflitos. Recorrer ao Poder Judiciário, isto é, bater às portas do Estado à procura de uma solução deveria ser, isto sim, uma forma alternativa de resolução de controvérsias. 
A partir da década de noventa depara-se com uma ampliação do Acesso à Justiça o que está relacionado à questões culturais, sociais e econômicas, e consequentemente acarretou um grande aumento das demandas no Poder Judiciário, interferindo na prestação jurisdicional de qualidade. Desse modo surge um obstáculo ao acesso à justiça, posto que, a sobrecarga de trabalho, prejudica diretamente a efetivação do direito.

Nesse sentido, Walter Ceneviva tece as seguintes considerações:

Constato, em seguida, um paradoxo: o povo está distante da Justiça por causa do grande número de feitos submetidos à mesma Justiça. O congestionamento - sinal mais exterior da grande crise - impede que qualquer processo tenha andamento normal. Certo de que a Justiça tardia é injusta em si mesmo, o povo se ressente. É grande o número dos que, não tendo condições de esperar, preferem qualquer composição fora dos autos, ainda que prejudicial, desde que rápida. Nutre a morosidade e a realimenta.

Dessa forma, o aumento excessivo das demandas judiciais, somado a ideia do acesso à justiça, acabou por construir uma barreira ao acesso à justiça. O Estado-Juiz tornou-se incapaz de proporcionar a tutela dos direitos em tempo satisfativo. A busca por mais justiça é incompatível com a estrutura do Poder Judiciário, que não está preparado para essa explosão de litigiosidade.

Diante do exposto é perceptível que os anseios da população não são compatíveis com a atual condição do poder judiciário, estruturado apenas para remediar os conflitos e não para dissolvê-los antes mesmo da instauração da lide. Tornam-se necessários instrumentos judiciais mais eficazes para a resolução de conflitos e o Novo Código de Processo Judicial aposta na mediação como alternativa para auxiliar na resolução e diminuição das demandas.

Caio Rocha (2015) aponta a mediação como mecanismo capaz de dirimir o problema que assola o judiciário:

A mediação tende a exercer papel relevante na redução do congestionamento de demandas junto ao Poder Judiciário, o que já seria, a primeira vista, uma contribuição quantitativa para a resolução de conflitos. Mas haverá ainda contribuição qualitativa na distribuição de justiça, seja pelo fato de que, ao concorrer para desafogar o aparato estatal judicial, esse instituto estará ajudando a dar condições para que o Judiciário aprecie com mais atenção e em tempo razoável os casos que lhe são submetidos, seja porque as próprias soluções produzidas pela mediação vão sig- 
nificar uma melhora de qualidade do processo decisório, pois serão fruto da discussão e do consenso.

É inegável que o problema do congestionamento de nossos tribunais é estrutural e precisa de solução em suas bases. Ainda assim, espera-se que a mediação cumpra seu papel e proporcione a diminuição do contingente de litígios que ingressa diariamente no Judiciário, amenizando a problemática em questão.

\subsection{A falha no acesso a uma ordem jurídica justa}

Com relação ao acesso à justiça, é claro o entendimento que não basta ampliar o número de pessoas e causas que ingressam em juízo, mas é fundamental que haja uma estrutura jurisdicional capaz de satisfazer essa demanda e que ofereça resultados úteis e satisfatórios aos que se valem do processo.

Quando há falha no acesso à justiça, ou seja, insuficiência no trinômio (qualidade dos serviços jurisdicionais, tempestividade da tutela ministrada mediante o processo e à sua efetividade), verifica-se a insatisfação daquele que buscou no judiciário a resolução do seu problema e acabou frustrado diante de um processo demorado, uma decisão tardia e sem um resultado prático desejável.

Dessa forma o acesso à justiça não deve ser entendido apenas como a abertura das portas do judiciário à população, pois, dessa forma, seria necessária uma estrutura gigantesca para julgar toda essa excessiva demanda. Em contrapartida, esse acesso deve ser entendido como um aparato capaz de resolver os conflitos da população, julgar em tempo razoável e satisfazer todas as tutelas pretendidas.

Nesse diapasão Alvim (2014, p.3) tece a seguinte ponderação:

Como disse, o problema do acesso à Justiça não é uma questão de "entrada", pois, pela porta gigantesca desse templo chamado Justiça, entra quem quer, seja através de advogado pago, seja de advogado mantido pelo Poder Público, seja de advogado escolhido pela própria parte, sob os auspícios da assistência judiciária, não havendo, sob esse prisma, nenhuma dificuldade de acesso. O problema é de "saída", pois todos entram, mas poucos conseguem sair num prazo razoável, e os que saem, fazem-no pelas "portas de emergência", representadas pelas tutelas antecipatórias, pois a grande maioria fica lá dentro, rezando, para conseguir sair com vida. Este é o grande problema e o grande obstáculo que enfrentamos, cabendo à doutrina, através de concepções voltadas para a realidade brasileira, sem copiar modelos estrangeiros, contribuir para a forma- 
ção de uma onda de "descesso" (saída) da Justiça, para que o sistema judiciário se torne mais racional na entrada, mas, também, mais racional e humano na saída.

Ademais, o acesso à justiça não deve instigar ainda mais a litigância, já que o aumento de ações judiciais ocasiona desordem social e econômica. De modo algum, não deve-se confundir o acesso à justiça com mera disposição para litigar.

Marinoni (2010, p.180) profere interessante opinião acerca do tema:

Não há dúvida que a preocupação com a questão do acesso à justiça não deve levar ao estímulo à litigância. Descabe confundir acesso à justiça com facilidade de litigar. A propositura de uma ação tem profundas implicações de ordem pessoal e econômica, devendo constituir uma opção feita a partir de um processo de reflexão, em que sejam considerados, de modo racional, os prós e contras que podem advir da instauração de um processo judicial.

É indiscutível que o acesso à justiça significa muito mais que a abertura das portas do judiciário à população. A explosão de litigância tem provado que a falha no acesso à justiça, pois os processos entram, porém, o caminho de saída é muito longo. Processos tramitam por longo tempo e a satisfação do direito se arrasta por anos de espera.

Ademais, na tentativa de estabelecer alguma celeridade, constantemente são estabelecidas algumas metas pelos tribunais, a fim julgar algum tipo de demanda. No entanto, esse tipo de solução apenas preocupa-se com a produtividade numérica sem levar em consideração a qualidade das decisões proferidas. Assim, logicamente a prestação jurisdicional continua prejudicada.

\subsection{Mediação como alternativa viável na busca do acesso à justiça}

Consoante pensamento de Peluso (2010) "a litigiosidade é um vício que prende a mentalidade tanto da sociedade quanto dos magistrados". Assim, vem de longe a mentalidade de litigar em juízo, entregar o conflito para que um terceiro (o juiz) resolva.

E assim, com o vício da litigiosidade, as demandas judicias foram aumentando, até se tornarem um pesado óbice ao oferecimento da tutela jurisdicional de qualidade. A tutela jurisdicional efetiva, adequada e tempestiva praticamente tornou-se impossível e o Poder Judiciário quase que foi tomado por uma falência, tornando-se deficiente e incapaz e satisfazer os anseios da população. 
Diante dessa crise no Judiciário o instituto da mediação surge como alternativa capaz de diminuir as demandas judiciais, pois já tem a função de resolvê-las assim que chegam ao Judiciário, ou mesmo antes, quando é da vontade das partes.

A Mediação é apaziguadora e a proporciona a resolução do conflito de modo muito mais efetivo, restabelecendo as relações familiares, já que busca sempre a retomada da comunicação entre as partes, o que não ocorre após um processo judicial, que, pelo contrário, rompe os últimos laços de afeto que possam ainda existir entre as partes.

Nesse sentido, Bárbara de Landa Gonçalves $(20017$, p, 121) leciona que a centralização dos litígios no Poder Judiciário fez com que outras instituições perdessem seu poder de referência, enfraquecendo as relações familiares, espaciais e sociais. Ainda segundo a autora, "o produto de tudo isso é a formação de um cidadão solitário, atomizado, pouco suscetível ao diálogo, ao consenso, que espera do Estado-Juiz a solução para qualquer tipo de problema, até mesmo para aqueles problemas que não precisam passar, a priori, pelo crivo jurisdicional".

Dessa maneira, o instituto da mediação pode auxiliar muito na pacificação social, restabelecendo a comunicação entre as partes, sem a utilização de um procedimento adversarial, construindo um acordo que traz benefícios a ambos. Vislumbra-se que a mediação pode representar uma proposta que atenue a crise numérica de processos que assola o judiciário, e ainda, com a diminuição destes processos, proporcione maior ascensão à Justiça e mais efetividade na entrega da tutela jurisdicional, e, logicamente, com celeridade.

\section{CONSIDERAÇÕES FINAIS}

O instituto da mediação é um instrumento disposto Novo Código Civil - Lei $n^{0} 13.105 / 2015$, na iminência de entrar em vigor em nosso país, e como toda novidade, lança expectativas na comunidade jurídica que aguarda para que o acesso à justiça finalmente seja efetivado.

Estudou-se o esse novo dispositivo tecendo-se análises acerca da atual crise numérica de processos que assola o Poder Judiciário, e ainda, que resulta em óbice ao acesso à justiça, tão conclamado pela população.

Assim, diante da caótica situação do judiciário a mediação poderá ser aplicada como método alternativo para diminuição das demandas, proporcionando a autocomposição das partes que serão auxiliadas por um mediador, e poderão alcançar o resultado mais favorável para ambas, conforme já foi ressaltado no presente trabalho.

Finalmente, é impossível apontar com certeza sobre o sucesso desse novo instituto, no entanto, na busca pela efetividade do acesso à justiça, esse será 
um meio que poderá proporcionar o desafogamento do judiciário e a consequente celeridade que é tão reclamada pelos jurisdicionados.

\section{REFERÊNCIAS}

ALVIM, C. J. E. Justiça: Acesso e Descesso. Jus Navigandi, Teresina, ano 8, n. 65, 1 maio 2003. Disponível em: http://jus.com.br/artigos/4078. Acesso em: 10 maio. 2015.

ASSIS, A. Garantia de acesso à Justiça: benefício da gratuidade. Porto Alegre: Ajuris. v. 73, 1998.

CAPELLETTI, M. Acesso à Justiça. Porto Alegre: Fabris, 1988.

CENEVIVA, W. Afastamento entre o judiciário e o povo: "uma reavaliação". In: TEIXEIRA, S. de F. (coord.). O judiciário e a Constituição. São Paulo: Saraiva, 1994, p. 254. Disponível em: http://emam.org.br/artigos. Acesso em: 10 abr. 2015.

CINTRA, A. C.; DINAMARCO. C. R.; GRINOVER, A. P. Teoria Geral do Processo. 21. ed. São Paulo: Malheiros, 2005.

GONÇALVES, B. L. Acesso e Decesso à Justiça: Litigância Abusiva e a Crise da Efetividade do Judiciário. 121 f. 2007. Dissertação (Mestrado em Direito) Universidade Estácio de Sá, Rio de Janeiro, 2007.

LEITE, M. F. Direito de família e mediação: a busca para resolução pacífica na disputa de guarda dos filhos. 2008. IBDFAM. Disponível em: www.ibdfam. org.br/?artigos\&artigo=436. Acesso em: 06 maio 2015 .

MARINONI, L. G.; ARENHART, S. C. Curso de Processo Civil: Procedimentos Especiais. 4. ed. vol. 5. São Paulo: Revista dos Tribunais, 2013. Ebook.

MARINONI, L. G. Precedentes obrigatórios. São Paulo: Revista dos Tribunais, 2010 .

MedinA, J. M. G.; WAMBIER, T. A. A. Parte Geral e Processo do Conhecimento. São Paulo: Revista dos Tribunais, 2013. Ebook.

MORALLES, L. C. P. Acesso à justiça e princípio da igualdade. Porto Alegre: Sergio Fabris, 2006. 
PELUSO, C. Revista Consultor Jurídico, agosto, 2010. Entrevista. Disponível em: http://www.conjur.com.br/2010-ago-11/entrevista-cezar-peluso-presidentesupremo-tribunal-federal. Acesso em: 11 abr. 2015.

SALES, L. M. de M. Justiça e mediação de conflitos. Belo Horizonte: Del Rey, 2004.

ROCHA,C. C. V; SALOMÃO, F. L. Arbitragem e mediação: a reforma da legislação brasileira. São Paulo: Atlas, 2015.

WATANABE, K. Participação e Processo. São Paulo: Revista dos Tribunais, 1988. 